\title{
Occurrence and Some Properties of a Green Pigment in the Erythrocytes of Scombroid Fishes
}

\author{
Shin-ya Fuke*, Katsumi Yamaguchi*, Kanehisa Hashimoto*, \\ and Fumio MATSUURA* \\ (Received August 10, 1973)
}

\begin{abstract}
A green pigment was found in the lyzates of erythrocytes from scombroid fishes such as mackerel, skipjack, albacore, etc. It migrated much faster than hemoglobin in starch block electrophoresis at pH 8.6. On Sephadex G-25 gel filtration, the pigment separated into three to six components depending upon the species of fish. The colors of those components generally were slightly different from each other. The green pigment to hemoglobin ratios were estimated to be $1 / 100$ or less in the erythrocytes of these fishes.

The green pigment was soluble in water and acetic acid, but not in any of the other organic solvents tested. The aq. solution of the pigment exhibited a characteristic absorption spectrum with a prominent maximum at $370-400 \mathrm{~m} \mu$ and a rather broad one at 600$650 \mathrm{~m} \mu$, suggesting the presence of biliverdin or a related substance as the chromophore. Qualitative examination showed that the pigment is a complex substance consisting of lipid, peptide, sugar, and phosphate in addition to the chromophore.
\end{abstract}

In the course of electrophoretic isolation of hemoglobin from the mackerel erythrocytes, we observed a fine green band migrating rapidly to the anode. The presence of such pigment in the red cells of either fish or any other animal has not been reported so far. Hence it seemed interesting from the viewpoint of comparative biochemistry to isolate and characterize the said green pigment, and the present investigation was started.

To begin with, the erythrocyte lyzates of many kinds of fishes were analyzed for the green pigment, and it was found that the pigment occurs only in scombroid fishes such as mackerel, skipjack, tunas, etc. Then, the pigment was isolated from the erythrocytes of some scombroids, and examined for several properties. Its constituents were qualitatively analyzed. Results obtained showed that the green pigment is a complex substance consisting of at least biliverdin or biliverdin-like chromophore, lipid, peptide, sugar, and phosphate.

\section{Experimental}

Blood samples Blood samples were obtained from the following fishes.

Scombroid fishes: mackerel ("masaba") Scomber japonicus, skipjack ("katsuwo") Katsuwonus pelamis, frigate mackerel ("sohdagatsuwo") Auxis thazard, albacore ("binnaga") Thunnus alalunga, bluefin tuna ("maguro") Thunnus thynnus, yellowfin tuna

* Lab. of Marine Biochem., Fac. of Agr., The Univ. of Tokyo, Bunkyo-ku, Tokyo

（福家真也·山口勝已·橋本周久·松溥文雄：東京大学㤟学部） 
("kihada") Neothunnus albacore, and bigeye tuna ("mebachi") Parathunnus obesus.

Other fishes: thresher ("onagazame") Alopias vulpinus, porbeagle ("mohkazame") Lamma ditropis, blue shark ("yoshikirizame") Prionace glaucus, sardine ("maiwashi") Sardinops melanosticta, chum salmon ("sake") Oncorhynchus keta, carp ("koi") Cyprinus carpio, crucian carp ("funa") Carassius auratus, loach ("dojo") Misgurnus anguillicaudatus, catfish ("namazu") Parasilurus asotus, conger ("ma-anago") Astroconger myriaster, eel ("unagi") Anguilla japonica, horse-mackerel ("ma-azi") Trachurus japonicus, yellowtail ("hamachi") Seriola quinqueradiata, sea bass ("suzuki") Lateolabrax japonicus, gilthead ("kurodai") Mylis macrocephalus, red sea-bream ("madai") Chrysophrys major, swellfish ("torafugu") Fugu rubripes, 3 kinds of flatfishes, ("hirame") Paralichthys olivaceus, ("magarei") Limanda herzensteini, and ("ishigarei") Kareius bicoloratus, and blue-white dolphin ("suziiruka") Stenella caeruleoalba as a control.

Blood was collected generally from the live specimens or the ones iced for from several hours to a few days. In the case of mackerel, blood was sampled from both the live and the iced specimens for comparison. As anticoagulant, $0.1 \mathrm{~m}$ potassium oxalate or Alsever's solution ${ }^{11}$ was used. With any species, the blood was collected from several to scores of individuals and combined. With mackerel, 25 individual blood samples were also provided from the live specimens. In the case where the blood was collected outside our laboratory, the blood was transported to our laboratory with ice within a few hours after catch and treated immediately as described below.

The red cells were separated by centrifugation ( $3000 \mathrm{rpm} \times 15 \mathrm{~min})$, washed several times with 5-10 volumes of $1 \%$ saline, and lyzed with small amounts of water, and stroma was removed by centrifugation $(14,000 \mathrm{rpm} \times 15 \mathrm{~min})$. The supernatants were used for the following experiments. If necessary, the washed red cells were kept frozen at $-20^{\circ} \mathrm{C}$ until use.

Detection and isolation of the green pigment The hemolyzates thus obtained were subjected to starch block electrophoresis in a $0.05 \mu$ veronal buffer, $\mathrm{pH} 8.6$, using a plastic vessel. Electrophoresis was carried out at a potential gradient of about $10 \mathrm{v} / \mathrm{cm}$ for $18 \mathrm{hr}$ at $2-4^{\circ} \mathrm{C}$, and it was examined with naked eyes whether there appeared a green band. When the green band was observed, it was scraped out and extracted with cold distilled water. A portion of the extract was used to examine the heat stability after desalting by gel filtration with Sephadex G-10 column $(3 \times 50 \mathrm{~cm})$, and lyophilizing.

The remaining extract was concentrated by lyophilization and then subjected to Sephadex G-25 (fine) gel filtration using a $6 \times 40 \mathrm{~cm}$ column. Generally, the green pigment was separated into several components as mentioned below. The eluate of each component was collected, lyophilized, and analyzed. Sephadex G-10 column $(3 \times 50 \mathrm{~cm})$ was employed to remove veronal buffer from the eluate.

With the individual hemolyzates of mackerel, the zone electrophoretic method 
was not applicable because of scarcity of each hemolyzate. Therefore, the following method was adopted here. It is based on the greater heat stability of green pigment as described later: An equal volume of $0.5 \mathrm{~m}$ phosphate buffer, $\mathrm{pH} 6.5$, is added to the hemolyzate in a test tube, mixed, and heated for $5 \mathrm{~min}$ in boiling water. Under those conditions, mackerel hemoglobin is completely denatured and coagulated. ${ }^{2}$ After heating, the mixture is cooled and centrifuged ( $3000 \mathrm{rpm} \times 15 \mathrm{~min}$ ), and the supernatant was checked for the presence of green pigment. This method was employed only for detection of the green pigment in the erythrocyte lyzates of mackerel.

Analytical methods Absorption spectrum The green pigments prepared as above were dissolved in water and measured for absorption spectrum over the near-ultraviolet to visible region with a Beckman DU spectrophotometer or a model 14 Cary recording spectrophotometer.

Solubility The lyophilized green pigments were examined qualitatively for solubility in water, acetic acid, methanol, ethanol, acetone, diethyl ether, $n$-hexane, petroleum ether, and chloroform.

Heat stability Each of the lyophilized preparations of green pigments from mackerel and skipjack was dissolved with $0.25 \mathrm{M}$ phosphate buffer, $\mathrm{pH} 6.5$, in a test tube, and heated for $5 \mathrm{~min}$ in boiling water. After cooling with tap water, the solution was analyzed for absorption spectrum.

Qualitative examination Constituents of each green pigment were surveyed qualitatively. First, each pigment was extracted for lipid moiety with a chloroform-methanol mixture according to the method of FolCH $e t a^{l^{3}}$. The extract was subjected to thin layer chromatography on a plate coated with silica gel G (Merck Co., Ltd.) using a solvent system, n-butanol/diethyl ether/acetic acid $(90: 10: 1)^{4}$, or chloroform/methanol/ water $(65: 25: 4)^{5}$. The spots were visualized with either iodine vapor or the acid molybdate reagent.

The delipidated pigment was then examined for other constituent by the following reactions or reagents: Gmelin reaction for bile pigment, Greig-Leaback reagent for peptide $^{\text {b) }}$, the ninhydrin reaction for amino acid, and the acid molybdate reagent for phosphate. For detection of sugar, the delipidated green pigment was hydrolyzed with $2 \mathrm{~N} \mathrm{HCl}$ at $100^{\circ} \mathrm{C}$ for $1 \mathrm{hr}$ and passed through a Duolite $\mathrm{A}-4\left(\mathrm{H}^{+}\right)$column. To the resulting $\mathrm{HCl}$-free solution, Benedict and Molisch reactions were applied.

\section{Results and Discussion}

Occurrence of the green pigment The green pigment was detected only in the erythrocytes of scombroid fishes such as mackerel, skipjack, and albacore among the various kinds of fishes tested here. In the case of mackerel, the green pigment was similarly 
detected in both hemolyzates from the live specimens and the iced specimens. The pigments from both the live and the iced mackerel behaved indistinguishably in the subsequent Sephadex gel filtration. The presence of the green pigment was confirmed in all the 25 hemolyzate samples individually prepared. Moreover, either with mackerel or with skipjack, almost the same results were obtained regardless of the season or locality of catch.

All the above results lead us to the conclusion that the green pigment is an intrinsic, not artificial, substance in erythrocytes of scombroid fishes. After the electrophoresis, the green pigment of each scombroid fish was extracted from the starch cake with water. From the yield, the green pigment to hemoglobin ratios in the erythrocytes were roughly estimated to be $1 / 100$ or less.

Gel filtration of the green pigment The electrophoretically isolated green pigments of mackerel, skipjack, and albacore were subjected to Sephadex G-25 (fine) gel filtration, resulting in separation into three to six components depending upon the species, as seen in Fig. 1. Those components were named components I-III or I-IV in the order of elu-

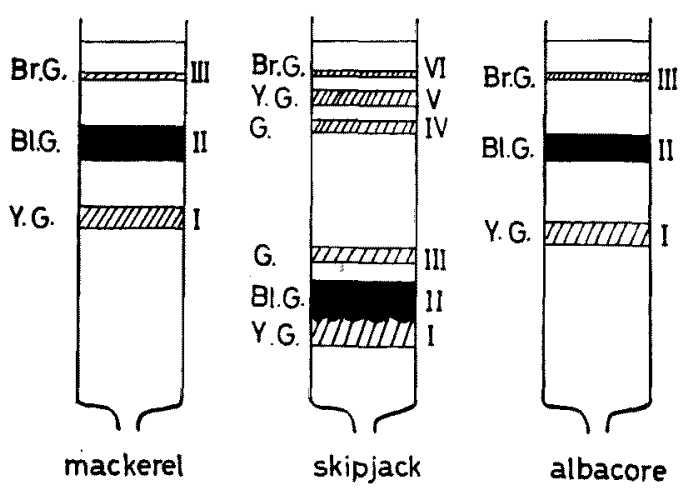

Fig. 1. Sephadex G-25 gel filtration of the green pigments of the three scombroid fishes. Br.G.=brownish green, Bl.G. = blue-green, Y.G. $=$ yellowish green, and $\mathrm{G} .=$ green. tion velocity: i.e., component I for the fastest and III or VI for the slowest depending upon fish species. The gel filtration pattern was confirmed to be almost constant with mackerel irrespective of the place or season of catch. So was the case with skipjack. The patterns of mackerel and albacore, both showing three components, resembled each other, except that component II of mackerel was more dominant than was that of albacore. On the other hand the skipjack pigment was easily separated into two groups in the gel filtration, each group subsequently being separated into three components. In this fish as well, component II was dominant.

Some properties of the green pigment The colors of the green pigments differed from each other between the components as seen in Fig. 1. However, the color of a given number of component was somewhat common through the three species of fish: e.g., component I was yellowish green and component II was blue-green.

All components of the three fishes resembled each other in absorption spectrum. The spectra of their components II are given in Fig. 2 as example, and the spectral 
characteristics of all the components are summarized in Table 1 . As seen in the figure and table, all of the green pigments, irrespective of the component and the species of fish, generally exhibited two peaks, a big one at $370-400 \mathrm{~m} \mu$, and a broad one at $600-650 \mathrm{~m} \mu$. The spectral characteristics of those two peaks seem to be a strong evidence for the presence of billiverdin or its related substance as the chromophore in the pigment.

All the components of the green pigments were found to be easily soluble in water and acetic acid,

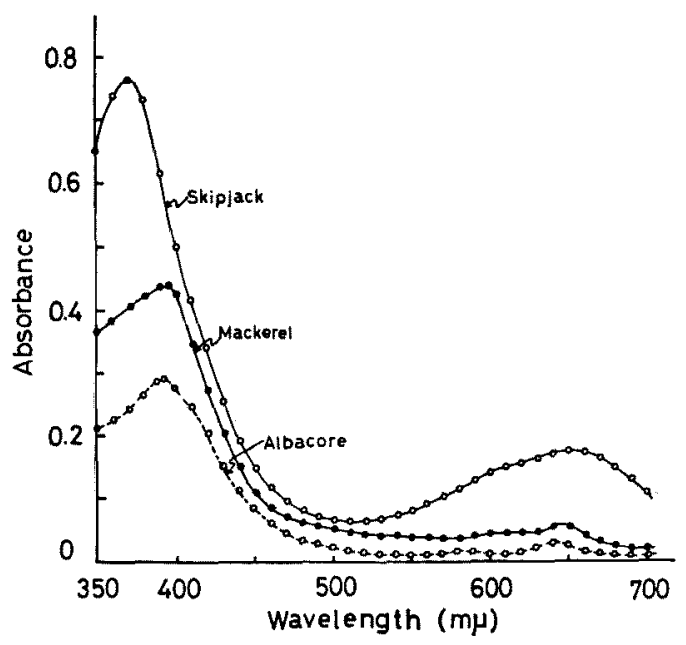

Fig. 2. Absorption spectra of the aq. solutions of components II of the three fishes.

Table 1. Spectral characteristics of the respective components of green pigments from the three scombroid fishes.

\begin{tabular}{|c|c|c|c|c|c|}
\hline \multirow{2}{*}{ Kind of fish } & \multirow{2}{*}{ Component } & \multicolumn{3}{|c|}{ Wavelength* } & \multirow{2}{*}{$\begin{array}{l}\text { Extinction ratio } \\
\qquad E_{\max _{3}} / E_{\max }\end{array}$} \\
\hline & & $\operatorname{Max}_{1}$ & $\mathrm{Max}_{2}$ & $\operatorname{Max}_{3}$ & \\
\hline \multirow{3}{*}{ Mackerel } & I & $376,(395)^{\mathrm{m} \mu}$ & $(590-5)^{m / s}$ & $642-4^{\mathrm{m} \mu}$ & 0.18 \\
\hline & II & $395-7$ & $(588-95)$ & $642-3$ & 0.14 \\
\hline & III & $396-8$ & $590-5$ & $(641-5)$ & $0.10^{* *}$ \\
\hline \multirow{6}{*}{ Skipjack } & I & 371 & - & 654 & 0.20 \\
\hline & II & $369-71$ & $(605)$ & 646 & 0.23 \\
\hline & III & $366-7$ & $(590-5)$ & $641-3$ & 0.21 \\
\hline & IV & 397 & $(600-5)$ & 642 & 0.11 \\
\hline & $\mathrm{V}$ & $397-8$ & 600 & - & $0.06^{* *}$ \\
\hline & VI & 395 & $(585-95)$ & $640-1$ & 0.19 \\
\hline \multirow{3}{*}{ Albacore } & I & $(390-5)$ & $(580)$ & 635 & 0.05 \\
\hline & II & $393-4$ & $(580)$ & $635-45$ & 0.06 \\
\hline & III & 395 & 590 & - & $0.07 * *$ \\
\hline
\end{tabular}

* Figures in parenthesis indicate shoulders.

** $\mathrm{E}_{\max 2} / \mathrm{E}_{\max }$.

slightly soluble in methanol, and insoluble in the other orgnaic solvents.

The green pigment solutions of mackerel and skipjack presented no precipitates and remained unchanged in color when heated under the above conditions. As Fig. 3 shows, the absorption spectrum was affected only slightly by the heating.

Constituents of the green pigment Lipid was extracted from all the green pigment 


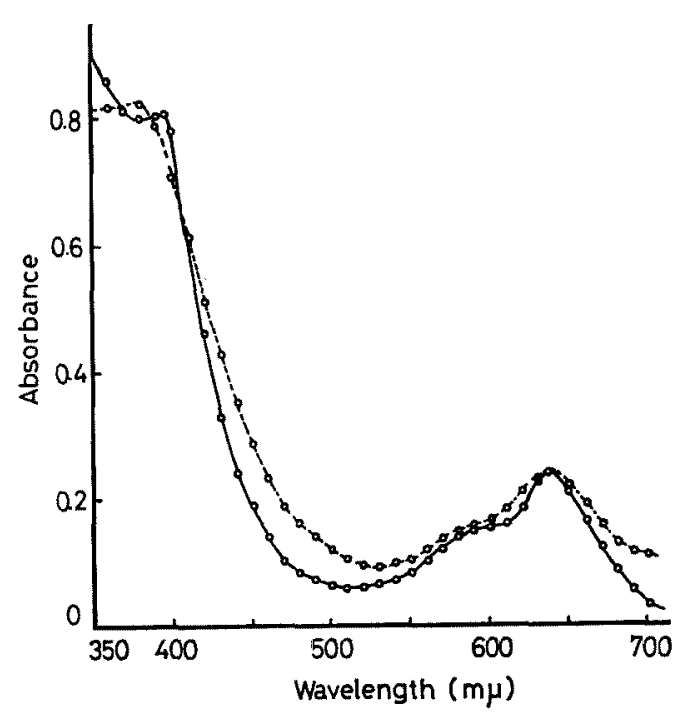

Fig. 3. Absorption spectra of the skipjack green pigment beofre $(\mathrm{O}-\mathrm{O})$ and after $(\mathrm{O}-\mathrm{O})$ heating for $5 \mathrm{~min}$ in boiling water. Refer to the text for further detail of the condition.

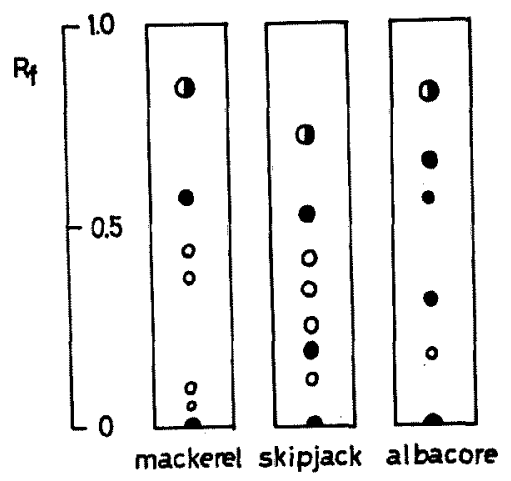

Fig. 4. This layer chromatograms of chloroformmethanol-soluble lipid from components II of the three fishes. Solvent: chloroform/methanol/water $(65: 25: 4)$. After the run, spots were detected with iodine vapor (O), and the acid molybdate reagent (๖). The spots positive to both reagents were shown by (a). components showing that it is a constituent of the pigment. The lipid fraction of each component was separated into several iodineor the acid molybdate-positive spots by thin layer chromatography. Some of those spots were positive to both reagents, indicating the possibility of phospholipid, as given in Fig. 4. The chromatograms showed some variations from component to component.

On the other hand, the delipidated portions of all the components were positive to Gmelin reaction, in agreement with the above inference based on the spectral characteristics that the chromophore could be biliverdin or its related substance. They were positive to the ninhydrin and GreigLeaback reagents, deomonstrating the presence of peptide.

The delipidated green pigments were all positive to the acid molybdate reagent, suggesting the presence of phosphate which is in a form other than phospholipid detected in the lipid fraction. The $\mathrm{HCl}$-hydrolyzates of those delipidated portions were positive to Benedict and Molisch reactions, proving the presence of some sugar in the molecule of green pigment.

Thus it is concluded that the green pigment is composed of at least biliverdin or its related substance, lipids including phospholipid, peptide, sugar, and phosphate. 


\section{Acknowledgements}

The authors wish to express their heartfelt thanks to Dr. A. Suzuki, Tokai Reg. Fish. Res. Lab., to Mr. H. TAKAHAShI, Gyogyo-Chishiki-Fukyu-Kai, to Mr. I. Warashina, Far Seas Fish. Res. Lab., to Mr. T. TANAKA, Tohoku Reg. Fish. Res. Lab., to Director K. Matsuura, Fish. Exp. Stn. of Shizuoka Pref., to Mr. A. Kumamoto, Inatori Fishermen's Cooperative Association, and Mr. K. Hiramoto, Fish. Exp. Stn. of Chiba Pref., for supply of blood samples. Thanks are also due to Mr. Miyajima, Fuji Seifun Co., Ltd., for his aid in the present experiment.

This work was supported in part by a grant from the Ministry of Education.

\section{References}

1) J. H. Currs: "Cell Separation Method in Hematology", 1st ed,, Academic Press, New York and London, 1970, p. 180.

2) F. Matsuura, K. Hashimoto, and N. Haruta: This Bull., 24, 730-734 (1959).

3) J. Folch, M. Lees, and G. H. Sloane-Stanley： J. Biol. Chem., 226, 497-509 (1957).

4) H. KANEKo, and Y. KAWANISHI: Yukagaku, 12, 597-604 (1963).

5) M. Mori, T. Saito, and Y. Watanabe: This Bull., 31, 448-451 (1965),

6) C. G. Greig, and D. H. LeABACK: Nature, 188, 310-311 (1960). 